\title{
Locally advanced cervical cancer with bladder invasion: clinical outcomes and predictive factors for vesicovaginal fistulae
}

\author{
Roger Sun ${ }^{1,2}$, Ines Koubaa ${ }^{3}$, Elaine Johanna Limkinn ${ }^{1,2}$, Isabelle Dumas ${ }^{4}$, Enrica \\ Bentivegna $^{5}$, Eduardo Castanon ${ }^{6}$, Sébastien Gouy ${ }^{5}$, Cynthia Baratiny ${ }^{1}$, Fyo \\ Monnot $^{1}$, Pierre Maroun ${ }^{1}$, Samy Ammari ${ }^{3}$, Elise Zareski ${ }^{3}$, Corinne Balleyguier ${ }^{3}$, Éric \\ Deutsch $^{1,2,7}$, Philippe Morice ${ }^{5,7}$, Christine Haie-Meder ${ }^{1}$ and Cyrus Chargari ${ }^{1,2,8,9}$ \\ ${ }^{1}$ Department of Radiotherapy, Gustave Roussy Cancer Campus, Villejuif, France \\ ${ }^{2}$ INSERM U1030 Molecular Radiotherapy, Gustave Roussy Cancer Campus, Villejuif, France \\ ${ }^{3}$ Department of Radiology, Gustave Roussy Cancer Campus, Villejuif, France \\ ${ }^{4}$ Department of Medical Physics, Gustave Roussy Cancer Campus, Villejuif, France \\ ${ }^{5}$ Department of Surgery, Gustave Roussy Cancer Campus, Villejuif, France \\ ${ }^{6}$ Department of Drug development, Gustave Roussy Cancer Campus, Villejuif, France \\ 7 Université Paris Sud, Université Paris-Saclay, Le Kremlin-Bicêtre, France \\ ${ }^{8}$ Institut de Recherche Biomédicale des Armées, Brétigny-sur-Orge, France \\ ${ }^{9}$ French Military Health Service Academy, Ecole du Val-de-Grace, Paris, France \\ Correspondence to: Cyrus Chargari, email: cyrus.chargari@gustaveroussy.fr \\ Keywords: cervical cancer; locally advanced; brachytherapy; bladder invasion; vesicovaginal fistula \\ Received: August 29, $2017 \quad$ Accepted: January 01, $2018 \quad$ Published: January 18, 2018 \\ Copyright: Sun et al. This is an open-access article distributed under the terms of the Creative Commons Attribution License 3.0 \\ (CC BY 3.0), which permits unrestricted use, distribution, and reproduction in any medium, provided the original author and source \\ are credited.
}

\section{ABSTRACT}

Objective: We report outcomes of cervical cancer patients with bladder invasion (CCBI) at diagnosis, with focus on the incidence and predictive factors of vesicovaginal fistula (VVF).

Results: Seventy-one patients were identified. Twenty-one $(30 \%)$ had paraaortic nodal involvement. Eight had VVF at diagnosis. With a mean follow-up time of 34.2 months (range: 1.9 months-14.8 years), among 63 patients without VVF at diagnosis, $15(24 \%)$ developed VVF. A VVF occurred in $19 \%$ of patients without local relapses $(9 / 48)$ and $40 \%$ of patients with local relapse $(6 / 15)$. Two-year overall survival (OS), disease-free survival (DFS) and local control rates were $56.4 \%$ (95\% CI: $44.1-67.9 \%$ ), 39.1\% (95\% CI: 28.1-51.4\%) and $63.8 \%$ (95\% CI: $50.4-75.4 \%$ ), respectively. Para-aortic nodes were associated with poorer OS (adjusted HR $=3.78$, $P$-value $=0.001)$. In multivariate analysis, anterior tumor necrosis on baseline MRI was associated with VVF formation $(63 \%$ vs $0 \%$ at 1 year, adjusted-HR $=34.13,95 \%$ CI: 4.07-286, $P$-value $=0.001)$, as well as the height of the bladder wall involvement of $>26 \mathrm{~mm}$ (adjusted-HR $=5.08,95 \%$ CI: 1.38-18.64, $P$-value $=0.014$ ).

Conclusions: A curative intent strategy including brachytherapy is feasible in patients with CCBI, with VVF occurrence in $24 \%$ of the patients. MRI patterns help predicting VVF occurrence.

Methods: Patients with locally advanced CCBI treated with (chemo)radiation \pm brachytherapy in our institute from 1989 to 2015 were analyzed. Reviews of baseline magnetic resonance imaging (MRI) scans were carried out blind to clinical data, retrieving potential parameters correlated to VVF formation (including necrosis and tumor volume). 


\section{INTRODUCTION}

Cervical cancers with bladder invasion (CCBI) classified as stage IVA according to the International Federation of Gynecology and Obstetrics (FIGO) represent approximately $2 \%$ of cervical cancers. The prognosis is poor, with an estimated 5-year overall-survival (OS) of $20 \%$ [1]. Moreover, development of vesicovaginal fistulae (VVF) is frequent, with retrospective data showing that VVF occurs in up to $50 \%$ of stage IVA cases, with no established predictive factors $[2,3]$.

The current standard of care for locally advanced cervical cancers consists of concurrent cisplatin-containing chemotherapy followed by brachytherapy [4-7]. However, although brachytherapy (BT) is a mainstay of treatment, data are limited on its efficacy in stage IVA disease, with some suggesting that bladder infiltration is a contraindication to brachytherapy [6, 8-14].

This study aims to report treatment outcomes in this particular situation, with focus on the incidence of and predictive factors for VVF formation.

\section{RESULTS}

\section{Patients and tumors}

Seventy-one patients with CCBI were identified. Forty-five $(63.4 \%)$ received the totality of their treatment in our institute and $26(36.6 \%)$ were referred only for brachytherapy, after having received external beam radiotherapy (EBRT) in other centers.

Patients' characteristics are summarized in Table 1. Forty-eight patients $(67.6 \%)$ presented with stage IVA disease, and 23 (32.4\%) had extrapelvic metastases, including 18 (25.4\%) with para-aortic lymph node (PALN) metastases and five $(7.0 \%)$ with oligo-metastatic disease.

\section{Radiotherapy/brachytherapy characteristics}

Treatments delivered are summarized in Table 2. All patients had pelvic radiotherapy, 23 had extended field (PALN) irradiation (32.4\%). Fifty-seven (80.3\%) received chemotherapy: 47 (66.2\%) received concomitant chemotherapy (cCRT), three (4.2\%) received neoadjuvant chemotherapy, seven $(9.9 \%)$ received both neoadjuvant and cCRT.

After EBRT, 64/71 (90\%) patients received BT boost: 2D-low dose rate brachytherapy (LDR-BT) for 33 patients, image-guided pulse-dose-rate brachytherapy (PDR-BT) for 31 patients (magnetic resonance imaging (MRI)-guided in 25 and computed-tomography (CT)guided in six patients). Eight patients had an interstitial boost (seven with PDR-BT, one with LDR-BT). From the beginning of EBRT to the end of BT, median overall treatment time was 54 days (range:42-143). Brachytherapy characteristics are detailed in Supplementary Table 1.
Seven patients did not receive brachytherapy: two had an EBRT boost (one refused BT, one had a major VVF contra-indicating BT); two underwent completion surgery by anterior pelvectomy after 45 Gy (Supplementary Figure 1). Seven patients $(10 \%)$ did not complete the radiotherapy (median dose: $39.6 \mathrm{~Gy}$, range: $30-43.2$ ): three for declining performance status, four for toxicities but the latter received brachytherapy.

\section{Dosimetric parameters}

Dosimetric parameters are summarized in Table 2. Median point A dose was $72.1 \mathrm{~Gy}_{\alpha / \beta 10}$ (range: $30.9-88.8$ $\left.\mathrm{Gy}_{\alpha / \beta 10}\right)$. Median International Commission on Radiation Units (ICRU) bladder point dose was $71.9 \mathrm{~Gy}_{\alpha \beta 3}$ (range: 16.1-109.2 $\mathrm{Gy}_{\alpha / \beta 3}$ ) and median ICRU rectal point dose was 74.7 $\mathrm{Gy}_{\alpha \beta 3}$ (range: $31.6-105.5 \mathrm{~Gy}_{\alpha \beta \beta}$ ). The treated volume (volume of $60 \mathrm{~Gy}$ isodose) and ICRU rectal point dose were significantly lower with PDR-BT (245.5 vs 294.1 cc, $P$-value $=0.01$ and 71 vs $77.4 \mathrm{~Gy} \alpha / \beta 3, P$-value $=0.02$ respectively) than with LDR-BT.

For the 31 patients treated by image-guided PDR$\mathrm{BT}$, the median high risk clinical target volume (HR-CTV) and intermediate risk clinical target volume (IR-CTV) were $41.6 \mathrm{~cm} 3$ (range: $11.1-113.2$ ) and $109.5 \mathrm{~cm} 3$ (range: 43.7-224.5), respectively. Median total doses delivered to $90 \%$ of the IR-CTV and HR-CTV were $61.75 \mathrm{~Gy}_{\alpha / \beta 10}$ (range: 55.2-76.4 $\mathrm{Gy}_{\alpha \beta 11}$ ) and $70.70 \mathrm{~Gy}_{\alpha / \beta 10}$ (range: $57.80-$ $\left.94.90 \mathrm{~Gy}_{\alpha \beta 10}\right)$, respectively.

\section{Treatment outcome}

After a mean follow-up time of 34.2 months (range: 1.9 months -14.8 years), persistent or recurrent disease was reported in 36/71 patients (50.7\%). Distant failure was the most common cause of disease progression (25/71 patients [35.2\%]). Pelvic lymph node failure was seen in $8 / 71$ patients $(11.2 \%)$. Local recurrences (LR) occurred in $16 / 71$ patients $(22.5 \%$ ), with eight having only LR (11.3\%). Thirteen of the 16 LRs and 7/8 isolated relapses were in patients who had pelvic only disease at diagnosis.

At the time of analysis (October 2016), 15 patients were alive, including 14 without evidence of disease. Three other patients had stopped their follow-up after more than 10 years of follow-up. Eight patients (11\%) were lost to follow up after the treatment (mean follow-up time: $235 \pm 179$ days). Estimated 2-year and median OS were $56.4 \%$ (95\% CI: 44.1-67.9\%) and 27.3 months (95\% CI: 18.8-52.7 months) respectively. Estimated 2-year and median disease-free-survival (DFS) were 39.1\% (95\% CI: $28.1-51.4 \%)$ and 15.8 months (95\% CI: $12.0-29.6$ months) respectively. Local control (LC) rates were $73.1 \%$ (95\% CI: $61.0-82.5 \%)$ at 1 year and $63.8 \%$ (95\% CI: $50.4-75.4 \%$ ) at 2 years (Figure 1).

In patients with only pelvic disease, 2-year and median OS and DFS were $68.8 \%$ (95\% CI: $54.2-80.4 \%$ ) 
Table 1: Patients characteristics

\begin{tabular}{|c|c|c|}
\hline Characteristics & & No. of patients $(\%)$ \\
\hline$N$ & & 71 \\
\hline \multirow[t]{5}{*}{ Age (years) } & Mean \pm SD & $53.7 \pm 13.7$ \\
\hline & $\leq 45$ & $22(31.0)$ \\
\hline & $46-55$ & $18(25.4)$ \\
\hline & $56-65$ & $15(21.1)$ \\
\hline & $\geq 66$ & $16(22.5)$ \\
\hline \multirow[t]{4}{*}{ PS } & 0 & $13(18.3)$ \\
\hline & 1 & $41(57.7)$ \\
\hline & 2 & $14(19.7)$ \\
\hline & 3 & $3(4.2)$ \\
\hline \multirow[t]{3}{*}{ Follow-up time (months) } & Median & 19.9 \\
\hline & Mean \pm SD & $34.2 \pm 38.4$ \\
\hline & Range & $1.9-177.4$ \\
\hline \multirow[t]{2}{*}{ Tumor characteristics } & Maximum tumor diameter $(\mathrm{mm})$ : mean $\pm \mathrm{SD}$ & $67.0 \pm 21.4$ \\
\hline & Tumor volume $(\mathrm{cc})$ & $112.71 \pm 97.47$ \\
\hline \multirow[t]{5}{*}{ Invasion of bladder } & Histologically proven & $15(21.1)$ \\
\hline & Cystoscopy & $13(18.3)$ \\
\hline & Laparoscopy & $1(1.4)$ \\
\hline & MRI & $39(54.9)$ \\
\hline & CT scan & $3(4.2)$ \\
\hline Invasion of rectum & & $13(18.3)$ \\
\hline \multirow[t]{2}{*}{ Fistula at diagnosis } & Bladder & $8(11.3)$ \\
\hline & Rectum & $1(1.4)$ \\
\hline \multirow[t]{4}{*}{ Parametrial invasion } & Unilateral & $8(11.3)$ \\
\hline & Bilateral & $61(85.9)$ \\
\hline & No & $2(2.8)$ \\
\hline & Clinical distal parametrial involvement & $45(63.4)$ \\
\hline \multirow[t]{3}{*}{ Vaginal invasion } & Yes & $55(77.5)$ \\
\hline & Limited to the upper two-third & $36(50.7)$ \\
\hline & Lower third involvement & $19(26.8)$ \\
\hline \multirow[t]{3}{*}{ Hydronephrosis } & Unilateral & $37(52.1)$ \\
\hline & Bilateral & $20(28.2)$ \\
\hline & No & $14(19.7)$ \\
\hline \multirow[t]{2}{*}{ Stage (FIGO) } & IV A & $48(67.6)$ \\
\hline & IV B & $23(32.4)$ \\
\hline \multirow[t]{4}{*}{ Nodal involvement } & No & $24(33.8)$ \\
\hline & Pelvic nodes only & $26(36.6)$ \\
\hline & Para-aortic nodes only & $5(7.0)$ \\
\hline & Both pelvic and para-aortic & $16(22.5)$ \\
\hline \multirow[t]{4}{*}{ PALN involvement } & CT scan & $3(4.2)$ \\
\hline & MRI & $9(12.7)$ \\
\hline & PET & $8(11.3)$ \\
\hline & PALN dissection & $1(1.4)$ \\
\hline
\end{tabular}




\begin{tabular}{llc} 
Metastasis at diagnosis & Ovarian & $2(2.8)$ \\
& Peritoneal & $1(1.4)$ \\
& Dorsal vertebra & $1(1.4)$ \\
Para-aortic nodes laparoscopic & Supraclavicular node & $1(1.4)$ \\
staging & Positive & $1(1.4)$ \\
Histology & Negative & $11(15.5)$ \\
& Squamous cell carcinoma & $61(85.9)$ \\
Differentiation & Adenocarcinoma & $8(11.3)$ \\
& Other & $2(2.8)$ \\
& Low & $21(29.6)$ \\
& Moderate & $20(28.2)$ \\
& High & $19(26.8)$ \\
& Unknown & $11(15.5)$ \\
\hline
\end{tabular}

Abbreviations: SD: standard deviation; FIGO: International Federation of Gynecology, Obstetrics; CT: computed Tomography; MRI: magnetic resonance imaging. PALN: para-aortic lymph nodes.

Table 2: Characteristics of treatment

\begin{tabular}{llc}
\hline Characteristics & & No. of patients (\%) \\
\hline Chemotherapy & Neoadjuvant CT only & $3(4.2)$ \\
& cCRT & $47(66.2)$ \\
Number of cCRT cycles & Neoadjuvant + cCRT & $7(9.9)$ \\
& No CT & $14(19.7)$ \\
& $\leq 4$ & $40(56.3)$ \\
Radiotherapy: technique & $\geq 5$ & $24(33.8)$ \\
& Unknown & $7(9.9)$ \\
Radiotherapy: fields & 2DCRT & $19(26.8)$ \\
Sequential radiation boost & 3 DCRT & $35(49.3)$ \\
& IMRT & $5(7.0)$ \\
& Not detailed & $12(16.9)$ \\
Brachytherapy & Pelvic & $48(67.6)$ \\
& Pelvic + paraaortic & $23(32.4)$ \\
& Parametrium & $12(16.9)$ \\
OTT (from the start of RT to the end of BT, $\boldsymbol{n}=\mathbf{6 4 )}$ & $\leq 55$ days & $18(25.4)$ \\
& Pelvic nodes & $9(12.7)$ \\
& Para-aortic nodes & $33(46.5)$ \\
& LDR & $31(43.7)$ \\
\hline
\end{tabular}

\begin{tabular}{llcc}
\hline Dosimetric Parameters & & Mean \pm SD & N available \\
\hline Radiotherapy & Pelvic dose & $44.7 \pm 3.1$ & 71 \\
Brachytherapy & Points A dose $\left(\mathrm{Gy}_{\alpha / \beta 10}\right)$ & $71.1 \pm 9.2$ & 45 \\
& TRAK $\left(\mathrm{cGy} \cdot \mathrm{h}^{-1} \cdot \mathrm{m}^{-1}\right)$ & $2.0 \pm 0.4$ & 64
\end{tabular}




\begin{tabular}{|c|c|c|c|}
\hline \multirow[b]{2}{*}{ HR-CTV } & V15Gy ${ }_{\alpha / \beta 3}\left(\mathrm{~cm}^{3}\right)$ & $270.2 \pm 78.70$ & 63 \\
\hline & Volume $\left(\mathrm{cm}^{3}\right)$ & $48.9 \pm 27.6$ & 31 \\
\hline \multirow{3}{*}{ IR-CTV } & $\mathrm{D}_{90}\left(\mathrm{~Gy}_{\alpha / \beta 10}\right)$ & $72.6 \pm 9.7$ & 30 \\
\hline & Volume $\left(\mathrm{cm}^{3}\right)$ & $108.5 \pm 50.6$ & 31 \\
\hline & $\mathrm{D}_{90}\left(\mathrm{~Gy}_{\alpha / \beta 10}\right)$ & $63.1 \pm 5.0$ & 30 \\
\hline \multirow[t]{2}{*}{ Bladder } & $\mathrm{D}_{2 \mathrm{cc}}\left(\mathrm{Gy}_{\alpha / \beta 3}\right)$ & $74.7 \pm 6.5$ & 30 \\
\hline & $\operatorname{ICRU}\left(\mathrm{Gy}_{\alpha / \beta 3}\right)$ & $72.0 \pm 13.0$ & 57 \\
\hline \multirow[t]{2}{*}{ Rectum } & $\mathrm{D}_{2 \mathrm{cc}}\left(\mathrm{Gy}_{\alpha / \beta 3}\right)$ & $66.1 \pm 5.9$ & 30 \\
\hline & $\operatorname{ICRU}\left(\mathrm{Gy}_{\alpha / \beta 3}\right)$ & $74.5 \pm 13.9$ & 58 \\
\hline Sigmoid & $\mathrm{D}_{2 \mathrm{cc}}\left(\mathrm{Gy}_{\alpha / \beta 3}\right)$ & $57.8 \pm 6.7$ & 30 \\
\hline
\end{tabular}

Abbreviations: cCRT: concurrent chemoradiation; TRAK: total reference air kerma; ICRU: International Commission Radiation Units: HR-CTV: high-risk clinical target volume; IR: intermediate-risk clinical target volume: OTT: overall treatment time; RT: radiation therapy; LDR: low dose rate; PDR: pulse dose rate; BT: brachytherapy.

and 33.6 months (95\% CI: 26.3-94.2 months), and 47.1\% (95\% CI: $33.3-61.3 \%)$ and 19.7 months (95\% CI: $14-56.3$ months) respectively. LC rates at 1 and 2 years were $79.7 \%$ (95\% CI: $65.6-88.9 \%)$ and $68.0 \%(95 \% \mathrm{CI}$ : $52.3-80.5 \%)$.

Salvage pelvectomy was performed for three patients due to LR suspicion (Supplementary Figure 1). Histological examinations showed few tumor cells for one patient, and a complete response for a second patient. All the three patients were still alive at the last follow-up (OS: 11, 25, 40 months).

\section{Prognostic factors}

Univariate analyses are summarized in supplementary materials (Supplementary Table 2). Multivariate analyses are provided in Table 3. In univariate analysis, PALN involvement was associated with poorer OS (median: 13.4 vs 33.6 months, $\mathrm{HR}=3.52,95 \% \mathrm{CI}$ : $1.86-6.66, P$-value $<0.001$ ) and DFS (median: 8.5 vs 19.0 months, HR: $2.50,95 \%$ CI: $1.37-4.55, P$-value $<$ 0.01 ), but remained significant only for OS in multivariate analysis. Similar results were seen for performance status

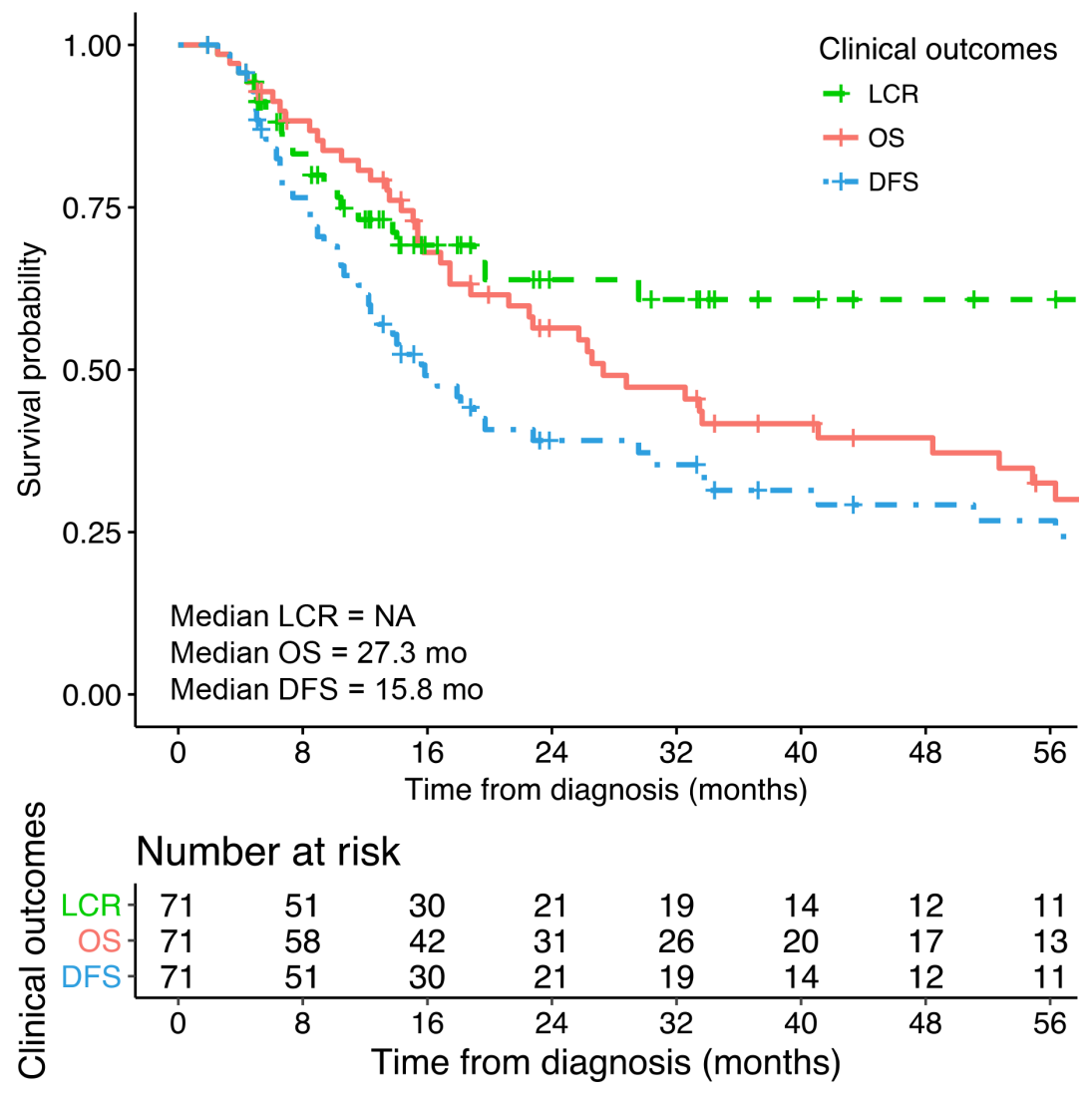

Figure 1: Overall survival (OS), disease free survival (DFS) times and local control rates (LCR). 
$(\mathrm{PS}) \geq 2(\mathrm{HR}=2.00,95 \% \mathrm{CI}: 1.07-3.74$, and $1.98,95 \%$ CI: $1.07-3.68$, for OS and DFS respectively) with nonsignificant P-values in multivariate analysis. Use of cCRT was associated with better outcomes for DFS ( $\mathrm{HR}=0.37$, 95\% CI: $0.20-0.68)$ and $\mathrm{LC}(\mathrm{HR}=0.29,95 \% \mathrm{CI}: 0.13$ 0.68 ), while the completion of the cCRT ( $\geq 5$ cycles) was associated with better $\mathrm{OS}(\mathrm{HR}=0.47,95 \% \mathrm{CI}: 0.24-0.92)$, in univariate analysis. In multivariate analysis, pelvic dose $<45$ Gy, use of concomitant chemotherapy, and tumor anterior-posterior diameter of $>5.5 \mathrm{~cm}$ were significantly associated with poorer LC (Table 3), Height of the bladder wall involvement was associated with DFS and LC rate in univariate analysis only $(\mathrm{HR}=2.07,95 \% \mathrm{CI}: 1.03-4.16$ and $\mathrm{HR}=3.38,95 \% \mathrm{CI}: 1.05-10.82)$. No relation could be drawn between points A or ICRU bladder/rectal point doses and probability of survival or LC. PDR-BT dose volume parameters could not be introduced in the model due to the limited number of patients treated with imageguided PDR-BT. VVF was not significantly associated with lower OS or DFS.

\section{Urinary outcome and fistula formation}

A total of 23 patients had VVF in their disease history. Eight patients had VVF prior to any treatment (11.3\% of the 71 patients) and four of them without urinary symptoms received brachytherapy. VVF disappearance was observed in two of them: one at 18 Gy of RT (cystoscopy), and one six months after BT (methylene blue test). Among the 63 patients (88.7\%) without VVF prior to treatment, 15/63 (23.8\%) developed VVF during follow-up, with $13 / 15$ (87\%) occurring the year following the start of radiotherapy (five before and ten after BT). Median time to onset was 3.1 months after the start of EBRT (95\% CI: 1.5-11.2 months). Six out of 15 VVFs $(40 \%)$ were associated with local relapse, while nine patients out of the 48 patients $(19 \%)$ with no VVF at diagnosis and no local relapse, developed a VVF which were therefore considered as complications.

Eleven of the 23 patients with VVF (48\%) underwent surgery related to VVF: anterior pelvectomy + cutaneous uretero-ileostomy $(n=5)$, isolated cutaneous uretero-ileostomy $(n=3)$, continent ileocolonic urinary reservoir $(n=1)$, total pelvectomy $(n=1)$, VVF repair $(n=1)$. Five patients also had a colostomy for associated recto-vaginal fistulae or severe digestive symptoms. At the last follow-up, $12 / 23$ patients $(52.2 \%)$ had no urinary symptom, while five $(21.7 \%)$ still experienced repeated urinary tract infections or dribbling.

\section{Predictive factors for VVF formation}

Univariate predictive factors tested for VVF formation in the population without VVF at diagnosis (63 patients) are provided in supplementary materials (Supplementary Table 3). Results of multivariate analysis are detailed in Table 3 and Supplementary Table 4.
Baseline MRIs were available for 43/63 (68\%) of patients without VVF at diagnosis. Anterior tumor necrosis was present in 18 patients, of which 12 developed VVF (Figure 2). Among the 25 patients without anterior tumor necrosis, one developed a VVF. Anterior tumor necrosis was significantly associated with the occurrence of VVF $(63 \%$ vs $0 \%$ at one year, $\mathrm{HR}=22.45,95 \% \mathrm{CI}: 2.91-$ 173.32, $P$-value $=1$ e-05) (Figure 3). Patients for whom the height of the bladder wall involvement was higher than the median of $26 \mathrm{~mm}$, seemed to have earlier onset of VVF at one year $(45 \%$ vs $16 \%$ at one year, $\mathrm{HR}=2.66,95 \% \mathrm{CI}$ : $0.87-8.20, P$-value $=0.08)($ Supplementary Figure 2$)$. In a multivariate analysis taking into account anterior necrosis and height of the bladder wall involvement, both variables were significant (Table 3).

\section{DISCUSSION}

CCBI is infrequent and data are scarce, generally showing poor prognosis and high local failure rates. This study with 71 patients, although retrospective, is to date the largest monocentric cohort assessing the clinical outcomes in this population, and one of the first examining prognostic factors associated with VVF $[15,2,3,16,17]$. Patient prognosis was poor, with median OS and DFS of 27.3 and 15.8 months, respectively. Approximately half of patients experienced tumor progression, distant relapses being the main cause of failure, and local recurrences affecting 16/71 (22.5\%) patients. These results are consistent with previously published data, reporting median OS and DFS of 21.2 and 10.1 months and 3yearOS and DFS of $47 \%$ and $28 \%$, respectively $[15,16]$. In contrast, a study of 34 patients with stage IVA cervical cancers reported a median OS of 49 months [17]. This difference could be explained by a large number of patients with stage IVB in our cohort $(32 \%)$. LC was nevertheless similar compared to previous retrospective studies of IVA cervical cancer, with local failure rates ranging from 39 to $44 \%[15,17]$.

Prognostic factors for tumor control and survival were identified in this subset of patients. PALN involvement was an independent poor prognostic factor for OS. Use of cCRT was a favorable prognostic factor in univariate, but not in multivariate analysis for OS and DFS, and remained significant in multivariate analysis for LC. Likewise, Moore et al. also reported a positive trend for survival benefit with chemotherapy in patients with stage IVA disease [2]. The median survival was 8.9 months for patients with stage IVA disease treated with radiation alone $(n=5)$ versus 22.6 months for patients treated with cCRT $(n=16)$, although this was not statistically significant [2]. The non-significance can be explained by the low number of patients in both studies. Moreover, the meta-analysis by Green et al. suggests that stage I-II patients benefit the most from cCRT for OS ( $P$-value $=0.009$ for trials randomizing $\geq 70 \%$ of stage 
I-II) [18]. The same trend was found in the Cochrane meta-analysis [19]. As for our results, the lower benefit of cCRT on OS may be due to the high incidence distant relapses, suggesting the importance of increasing not only local but also systemic treatment. Two international ongoing phase III studies aim to assess the survival benefit of additional chemotherapy delivered either before (the INTERLACE trial, NCT01566240) or after cCRT and brachytherapy (the OUTBACK trial, NCT01414608) for IB1-node positive to IVA disease.

The limited size of our cohort did not allow us to find any association between survival and 3D-dosimetric parameters, but application of GECESTRO guidelines [20-22] may improve the quality of radiotherapy and brachytherapy as suggested by Pötter et al, reporting an increase in OS and LC for tumors $>5 \mathrm{~cm}$ since the advent of MRI-based treatment planning, in an analysis of 145 patients with cervical cancer stages IB-IVA [23].

One major concern in patients receiving brachytherapy for stage IVA cervical cancer is the risk of VVF. It is frequently advocated that bladder involvement should be a contra-indication to brachytherapy because of a high risk of VVF formation. In this series wherein most patients received brachytherapy despite bladder involvement, we reported an acceptable rate of VVF. The $24 \%$ rate of VVFs occurring during or after treatment was comparable to the $22 \%$ reported in two previous studies where majority of patients received brachytherapy $[3,24]$ although this estimation is variable in literature, ranging from $<10 \%[15-17,25]$ to approximately $50 \%$ [2]. Tumor necrosis on baseline MRI, particularly anterior necrosis, was strongly associated with VVF formation, which occurred earlier when the height of the bladder wall involvement was high. If confirmed in further studies, such as the multicenter study EMBRACE (https://www. embracestudy.dk/), these MRI findings could be used for stratifying patients. So far, due to the lack of large cohorts, no strong predictive factor was identified. Moore et al. suggested that smoking was predictive of VVF formation in univariate analysis $(73 \%$ vs $27 \%, P$-value $=0.03$, among 11 patients with VVF), but this was not confirmed either by Biewenga et al. (HR 2.2 95\% CI: 0.4-13, $P$-value $=0.39$ ) or by our results $[2,3]$.

The main limitation of our study is its retrospective nature, with patients being treated over a large time interval, with consequent technique evolutions, leading to a nonnegligible amount of missing data (mainly baseline imaging
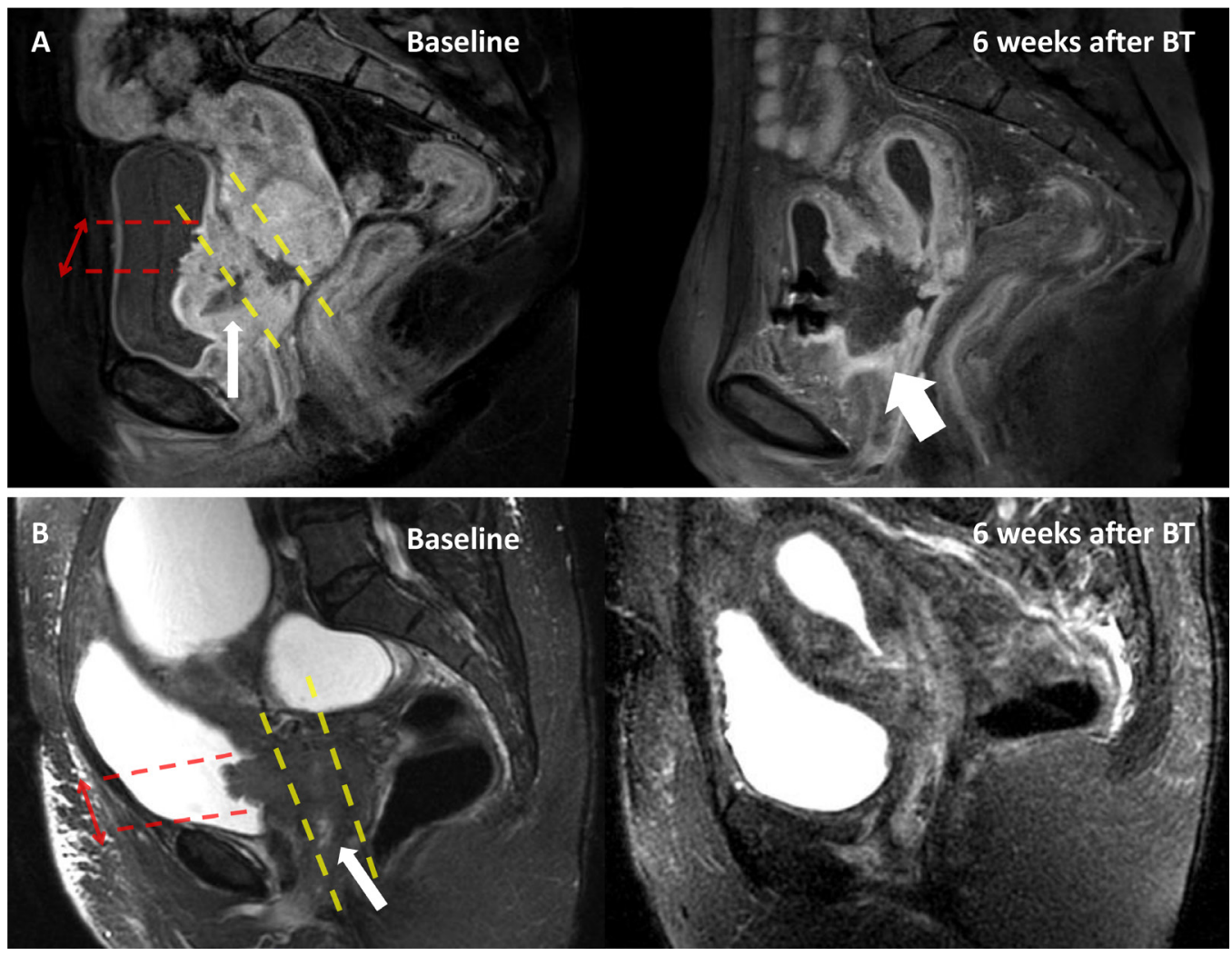

Figure 2: Example of anterior necrosis leading to VVF. Magnetic Resonance Imaging (MRI) exams of two patients with cervical cancer stage IVA (patient A: contrast enhanced T1-weighted MRI and patient B: T2-weighted MRI) at baseline (left), and 6 weeks after brachytherapy (right). Patient A had a tumor necrosis (thin arrow) which involved the anterior third of the tumor, while there was no anterior necrosis for patient B. Six weeks after brachytherapy (BT), patient A developed a vesicovaginal fistula (thick arrow), while patient B had a complete response. Red arrows: height of the bladder involvement. Yellow dashed line: delimit the anterior-third, mid-third and posteriorthird of the tumor. 
Table 3: Multivariate analysis of prognostic factors for overall survival, progression-free survival, local control and vesicovaginal fistula formation

\begin{tabular}{|c|c|c|c|c|}
\hline \multicolumn{5}{|c|}{ Overall survival } \\
\hline Multivariate analysis & Model & Cox-HR & CI 95\% & $P$-value \\
\hline Para-aortic nodes & $57 \mathrm{pts}$ & 3.78 & $1.75-8.19$ & $0.001^{*}$ \\
\hline Completion of Concomitant CT & 37 events & 0.57 & $0.28-1.18$ & 0.13 \\
\hline Tumor ant-post diameter $>5.5 \mathrm{~cm}$ & & 1.23 & $0.59-2.55$ & 0.58 \\
\hline Pelvic nodes & & 0.83 & $0.38-1.82$ & 0.64 \\
\hline $\mathbf{P S} \geq 2$ & & 2.78 & $1.30-5.92$ & $0.008^{*}$ \\
\hline \multicolumn{5}{|c|}{ Progression-free survival } \\
\hline Multivariate analysis & Model & Cox-HR & CI 95\% & $P$-value \\
\hline Use of Concomitant CT & $49 \mathrm{pts}$ & 0.51 & $0.22-1.15$ & 0.10 \\
\hline Tumor ant-post diameter $>5.5 \mathrm{~cm}$ & 34 events & 1.45 & $0.57-3.68$ & 0.44 \\
\hline Para-aortic nodes & & 1.84 & $0.73-4.61$ & 0.19 \\
\hline $\mathbf{P S} \geq 2$ & & 2.18 & $0.73-6.45$ & 0.16 \\
\hline ICRU bladder point > $70 \mathrm{~Gy}$ & & 1.55 & $0.72-3.31$ & 0.26 \\
\hline \multicolumn{5}{|c|}{ Local control rate } \\
\hline Multivariate analysis & Model 1 & Cox-HR & CI 95\% & $P$-value \\
\hline Use of Concomitant CT & $61 \mathrm{pts}$ & 0.36 & $0.13-0.95$ & $0.04^{*}$ \\
\hline Tumor ant-post diameter $>5.5 \mathrm{~cm}$ & 19 events & 3.01 & $1.04-8.75$ & $0.04^{*}$ \\
\hline Pelvic RT dose $<45$ Gy & & 10.88 & $2.92-40.40$ & $3.6 \mathrm{e}-4^{*}$ \\
\hline \multicolumn{5}{|c|}{ Vesicovaginal fistula formation } \\
\hline Multivariate analysis & Model & Cox-HR & CI 95\% & $P$-value \\
\hline MRI anterior necrosis & $43 \mathrm{pts}$ & 34.13 & $4.07-286$ & $0.001^{*}$ \\
\hline Height of bladder wall involvement $>26 \mathrm{~mm}$ & 13 events & 5.08 & $1.38-18.64$ & $0.014^{*}$ \\
\hline
\end{tabular}

Abbreviations: HR: hazard ratio; CT: chemotherapy, PS: Performance Status, RVF: rectovaginal fistula, VVF: vesicovaginal fistula.

"Significant $P$-value in multivariate analysis.

and LDR-BT dosimetric parameters). Moreover, all patients did not have histological confirmation of bladder invasion and those with clinical symptoms of VVF before any treatment were not considered for brachytherapy.

However, our data provide strong argument for the use of brachytherapy as part of the definitive treatment of selected CCBI. Brachytherapy is the best modality for dose escalation, paramount in this subset of patients with high frequency of local relapses. The incidence of VVF in patients who did not experience local relapse was acceptable; furthermore, majority of surviving patients had no urinary symptoms at their last follow-up [12-14]. The finding that $40 \%$ of patients with local relapses developed VVF emphasizes the need for aggressive and ideal treatment, including cCRT and optimal brachytherapy, which has been shown to be an independent favorable prognostic factor for OS in locally advanced cervical cancer [8]. Although the predictive value of MRI regarding occurrence of VVF need to be confirmed in a prospective cohort, knowledge of such factors may allow giving patients a more accurate information about VVF risk and associated symptoms.

To conclude, a curative intent strategy including brachytherapy as part of local treatment is feasible in patients with bladder invasion, with VVF formation in $24 \%$ of them. MRI has a strong predictive value for VVF occurrence. Since prognosis remains poor, intensification of local and systemic therapies should be considered.

\section{MATERIALS AND METHODS}

\section{Patient selection}

Clinical and dosimetric data of patients with CCBI treated in our Institute between 1989 and 2015 were retrospectively reviewed. Stage IVA was defined by a histologically proven bladder involvement by biopsy, a visual confirmation of bladder involvement by cystoscopy, and/or an unequivocal bladder involvement at CT or MRI 
or cystoscopy according to the radiologist. Patients with a stage IVA disease and treated with (chemo)radiation \pm brachytherapy were included. Patients with PALN involvement (suspected on imaging or confirmed after PALN dissection), or stage IVB oligo-metastatic disease who received local treatment with curative intent were also included. This retrospective study was conducted in accordance with ethical standards and with the 1964 Helsinki declaration and its later amendments.

\section{EBRT}

All patients received pelvic EBRT. Para-aortic irradiation was used if PALN metastases were suspected by imaging. From 2007, PALN dissection was performed on patients without para-aortic positron emission tomography-computed tomography (PET-CT) uptake to guide EBRT fields, based on retrospective data showing a high incidence of false negative PET-CT results in the para-aortic area [26-28].

EBRT was delivered using 1.8-2 Gy daily fractions, five fractions per week, with a total dose of 45 Gy. Two- dimensional conventional radiotherapy was used from 1989 to 2003, and 3D conformal radiotherapy was used since 2004. From 2014, patients receiving EBRT in our institution were treated with intensity-modulated radiotherapy. cCRT consisted of weekly cisplatin $\left(40 \mathrm{mg} / \mathrm{m}^{2} /\right.$ week) or weekly carboplatin AUC2 (in case of renal contra-indication), except in cases of patient's refusal or comorbidity.

A sequential or synchronous EBRT boost was given to deliver a total dose of 60 Gy to macroscopically involved nodes (pelvic or PALN), taking into account the contribution of brachytherapy.

\section{Brachytherapy}

After EBRT, patients without symptoms of VVF were candidates for an utero-vaginal brachytherapy boost, following a previously reported procedure [29-33]. LDR was delivered with Cesium-137 sources before 2006. Thereafter, PDR with Iridium-192 stepping source was used.

Treatment planning was based on radiographs or 3D imaging (CT or MRI), depending on the year of treatment. For radiograph-based planning, dosimetry

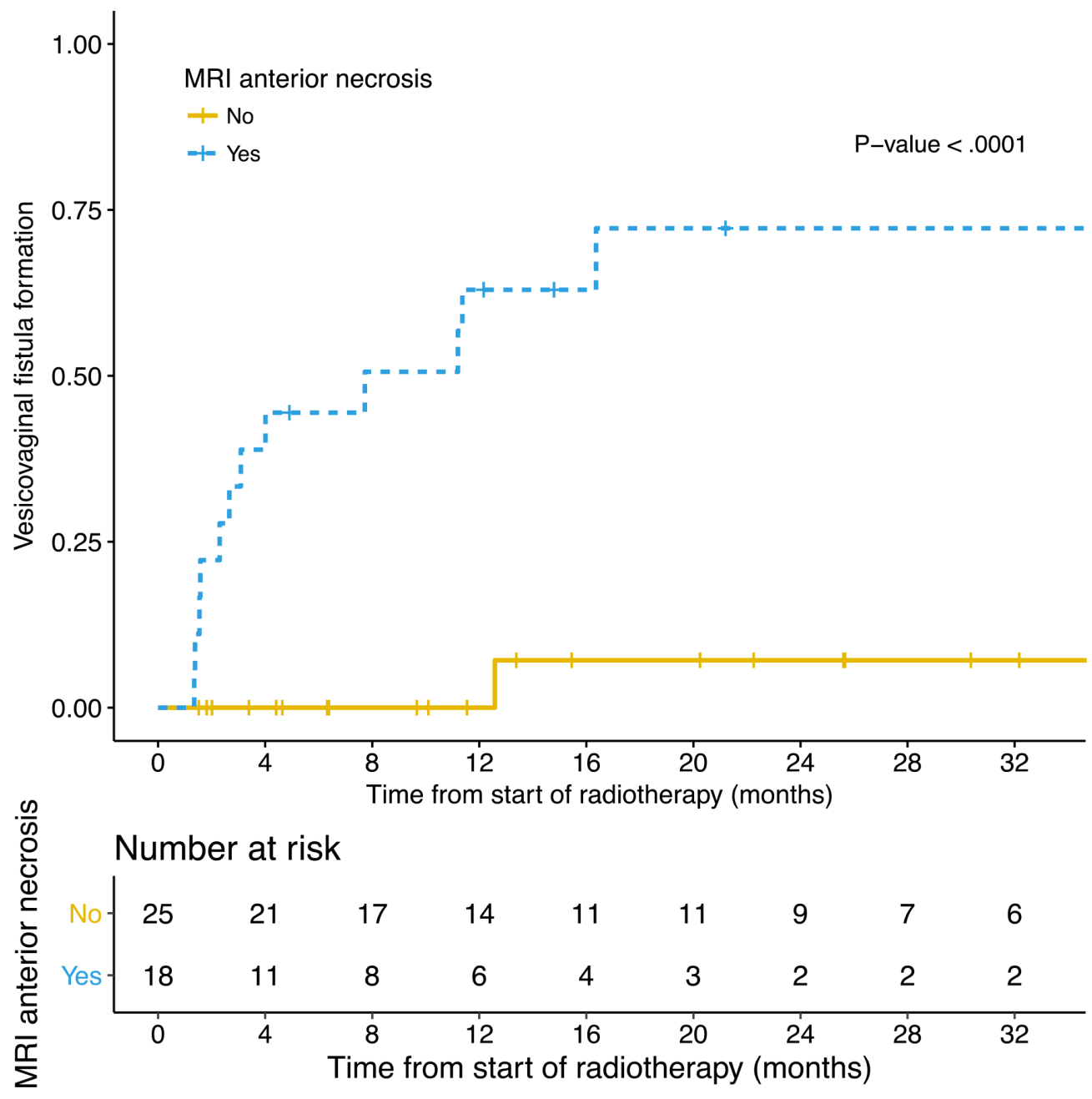

Figure 3: Rate of VVF formation according to the presence of MRI anterior necrosis. 
was based on orthogonal radiographs and 15 Gy was prescribed to the isodose that encompassed the cervix and residual tumor with a $0.5-1 \mathrm{~cm}$ margin in all three planes, without exceeding ICRU 38 dose constraints. For $3 \mathrm{D}$ treatments, tumor volumes and organs at risk (OARs) were delineated on T2-weighted MRI or CT scan. The aim was to deliver $\geq 60$ Gy to $90 \%$ of the IR-CTV, defined according to the Brachytherapy Group of the European Society of Therapeutic Radiology and Oncology (GECESTRO) guidelines, without exceeding dose constraints to the most irradiated $\mathrm{D} 2 \mathrm{~cm}^{3}$ of rectum, bladder and sigmoid colon $[20,34]$.

For PDR treatments, continuous hourly pulses were delivered, $24 \mathrm{~h}$ /day. For both LDR and PDR treatments, a dose rate of $0.6 \mathrm{~Gy} / \mathrm{h}$ to ICRU points or to the most irradiated D $2 \mathrm{~cm}^{3}$ of OARs was not exceeded. Interstitial needles were applied when necessary to improve tumor coverage, especially in the parametria. Contribution of interstitial catheters did not exceed $20 \%$ of the Total Reference Air Kerma (TRAK).

Doses delivered were reported after conversion into $2 \mathrm{~Gy} /$ fraction radiobiological dose equivalents, using the linear-quadratic model (repair half-time: $1.5 \mathrm{~h}, \alpha / \beta$ ratio $=10$ Gy and 3 Gy for target volumes and OARs, respectively [35].

\section{Surgery}

Post-radiation hysterectomy was discussed for patients who could not receive brachytherapy boost due to clinical symptoms of VVF, had residual disease 6-8 weeks after brachytherapy completion, or experienced local recurrence during follow-up. If indicated, surgery was an anterior pelvectomy $+/$ - urinary diversion. Patients with VVF and not indicated for BT boost could also receive an EBRT boost.

\section{Follow-up}

Patients were evaluated weekly during radiotherapy. Follow-up was ensured at 6 weeks following BT, then every 3 months for 2 years, every 6 months until year 5, then annually thereafter. MRIs were performed systematically 6 weeks after treatment completion, then every 6 months. Failures were classified according to the site of first tumor relapse and defined as centropelvic (cervix, uterine corpus, vagina, parametrium, bladder), regional (pelvic nodes), or distant (PALN or visceral).

\section{Statistical analysis}

Potential prognostic and predictive factors of VVF were examined from medical charts, and included tumor and treatment related variables (see Supplementary Materials), as well as detailed radiological characteristics of the tumor: volume, height of bladder wall involvement, tumor necrosis (high signal intensity on T2-weighted MRI, low signal with no enhancement on contrast-enhanced T1weighted MRI) and localization ("anterior" if involving the anterior third of the tumor) (Figure 2). Radiological parameters were double-blind assessed by R.S and I.K. In case of disagreement, imaging was assessed by a senior radiologist (S.A).

Wilcoxon tests and fisher tests were used for comparisons between variables. LC rate, DFS and OS were computed according to the Kaplan-Meier method and Cox's proportional-hazards survival estimates. For continuous variable analyses, median was used to separate patients into two groups. Follow-up and survival times were calculated from the date of histopathological diagnosis. Endpoint was any death for $\mathrm{OS}$, local recurrence for $\mathrm{LC}$, and any recurrence for DFS (including all-cause deaths for DFS, and death related to disease before any relapse for $\mathrm{LC}$ ). Time to VVF formation was estimated from the start of radiotherapy.

$P$-values were estimated using double-sided tests. A threshold of $<.05$ was defined for significance. Nonredundant variables with a $P$-value of $<.1$ were included in multivariate analyses. Statistical analyses were carried out using R version 3.3.2 [36] (http://www.R-project.org) and "survival" R-package (version 2.40-1 [37]).

\section{Abbreviations}

AUC: area under the curve; BT: brachytherapy; CCBI: cervical cancer patients with bladder invasion; cCRT: concomitant chemotherapy; CI: confidence interval; CT: computed tomography scan; EBRT: external beam radiotherapy; FIGO: International Federation of Gynecology and Obstetrics; GEC-ESTRO: Group of the European Society of Therapeutic Radiology and Oncology; HR: hazard-ratio; HR-CTV: high risk clinical target volume; I.C.R.U: International Commission on Radiation Units; IMRT: intensity-modulated radiotherapy; IR-CTV: intermediate risk clinical target volume; LDR: low dose rate brachytherapy; LC: local control rate; LR: local recurrence; MRI: magnetic resonance imaging; OAR: organ at risk; OS: overall survival; PALN : paraaortic lymph node; PDR: pulse dose rate brachytherapy; PET-CT: Positron emission tomography-computed tomography; DFS: disease-free survival; RT: radiotherapy; VVF: vesicovaginal fistula.

\section{Author contributions}

study concepts: RS, CG; Study design: RS, CG; Data acquisition: RS, IK, ID, SG, CB, FM, PM, EB, EZ, ED, PM; Quality control of data and algorithms: RS, EC, CG; Data analysis and interpretation: RS, IK, SA, ; Statistical analysis: RS, EC; Manuscript preparation: RS, CG; Manuscript editing: RS, CG, EJL, CHM; Manuscript review: EC, SG, PM, SA, CB, ED, PM, CHM, CG. 


\section{CONFLICTS OF INTEREST}

None.

\section{REFERENCES}

1. Kosary CL. Cancer of the cervix uteri In Cancer survival among adults: US SEER program, 1988-2001. Patient Tumor Charact. SEER Surviv Monogr Publ. 2007:07-6215, p117.

2. Moore KN, Gold MA, McMeekin DS, Zorn KK. Vesicovaginal fistula formation in patients with Stage IVA cervical carcinoma. Gynecol Oncol. 2007; 106:498-501. https://doi.org/10.1016/j.ygyno.2007.04.030

3. Biewenga P, Mutsaerts MA, Stalpers LJ, Buist MR, Schilthuis MS, van der Velden J. Can we predict vesicovaginal or rectovaginal fistula formation in patients with stage IVA cervical cancer? Int J Gynecol Cancer. 2010; 20:471-75. https://doi.org/10.1111/IGC.0b013e3181d224c8

4. National Comprehensive Cancer Network. Cervical Cancer [cited 2017 Aug 26]. https://www.ncen.org/professionals/ physician_gls/pdf/cervical.pdf.

5. Marth C, Landoni F, Mahner S, McCormack M, GonzalezMartin A, Colombo N, and ESMO Guidelines Committee. Cervical cancer: ESMO Clinical Practice Guidelines for diagnosis, treatment and follow-up. Ann Oncol. 2017; 28:iv72-83. https://doi.org/10.1093/annonc/mdx220.

6. Tanderup K, Lindegaard JC, Kirisits C, Haie-Meder C, Kirchheiner K, de Leeuw A, Jürgenliemk-Schulz I, Van Limbergen E, Pötter R. Image Guided Adaptive Brachytherapy in cervix cancer: A new paradigm changing clinical practice and outcome. Radiother Oncol. 2016; 120:365-69. https://doi.org/10.1016/j.radonc.2016.08.007.

7. Sun R, Mazeron R, Chargari C, Barillot I. CTV to PTV in cervical cancer: from static margins to adaptive radiotherapy. Cancer Radiother. 2016; 20:622-28. https:// doi.org/10.1016/j.canrad.2016.07.088.

8. Han K, Milosevic M, Fyles A, Pintilie M, Viswanathan AN. Trends in the utilization of brachytherapy in cervical cancer in the United States. Int J Radiat Oncol Biol Phys. 2013; 87:111-19. https://doi.org/10.1016/j.ijrobp.2013.05.033.

9. Eifel PJ, Moughan J, Erickson B, Iarocci T, Grant D, Owen J. Patterns of radiotherapy practice for patients with carcinoma of the uterine cervix: a patterns of care study. Int J Radiat Oncol Biol Phys. 2004; 60:1144-53. https://doi. org/10.1016/j.ijrobp.2004.04.063.

10. Tanderup K, Eifel PJ, Yashar CM, Pötter R, Grigsby PW. Curative radiation therapy for locally advanced cervical cancer: brachytherapy is NOT optional. Int J Radiat Oncol Biol Phys. 2014; 88:537-9. https://doi.org/10.1016/j. ijrobp.2013.11.011.

11. Ampil FL. Stage IV-A carcinoma of the cervix. Radiat Med. 1990; 8:184-87.

12. Bermudez A, Bhatla N, Leung E. Cancer of the cervix uteri. Int J Gynaecol Obstet. 2015; 131:S88-95. https://doi. org/10.1016/j.ijgo.2015.06.004.
13. Mahajan NN. Vesicovaginal fistula formation in patients with Stage IVA cervical carcinoma. Gynecol Oncol. 2008; 109:429, 429-30. https://doi.org/10.1016/j.ygyno.2008.02.021.

14. Moore K. Response to Dr. Mahajan. Gynecol Oncol. 2008; 109:429-30. https://doi.org/10.1016/j.ygyno.2008.02.022.

15. Rose PG, Ali S, Whitney CW, Lanciano R, Stehman FB. Outcome of stage IVA cervical cancer patients with disease limited to the pelvis in the era of chemoradiation: a Gynecologic Oncology Group study. Gynecol Oncol. 2011; 121:542-45. https://doi.org/10.1016/j.ygyno.2011.02.024.

16. Shiba S, Wakatsuki M, Kato S, Ohno T, Okonogi N, Karasawa K, Kiyohara H, Tsujii H, Nakano T, Kamada T, Shozu M, and The Working Group of the Gynecological Tumor. Carbon-ion radiotherapy for locally advanced cervical cancer with bladder invasion. J Radiat Res (Tokyo). 2016; 57:684-90. https://doi.org/10.1093/jrr/rrw070.

17. Murakami N, Kasamatsu T, Morota M, Sumi M, Inaba K, Ito Y, Itami J. Radiation therapy for stage IVA cervical cancer. Anticancer Res. 2013; 33:4989-94.

18. Green JA, Kirwan JM, Tierney JF, Symonds P, Fresco L, Collingwood M, Williams CJ. Survival and recurrence after concomitant chemotherapy and radiotherapy for cancer of the uterine cervix: a systematic review and metaanalysis. Lancet. 2001; 358:781-86. https://doi.org/10.1016/ S0140-6736(01)05965-7

19. Chemoradiotherapy for Cervical Cancer Meta-analysis Collaboration (CCCMAC). Reducing uncertainties about the effects of chemoradiotherapy for cervical cancer: individual patient data meta-analysis. Cochrane Database Syst Rev. 2010; 1:CD008285.

20. Haie-Meder C, Pötter R, Van Limbergen E, Briot E, De Brabandere M, Dimopoulos J, Dumas I, Hellebust TP, Kirisits C, Lang S, Muschitz S, Nevinson J, Nulens A, et al, and Gynaecological (GYN) GEC-ESTRO Working Group. Recommendations from Gynaecological (GYN) GEC-ESTRO Working Group (I): concepts and terms in 3D image based 3D treatment planning in cervix cancer brachytherapy with emphasis on MRI assessment of GTV and CTV. Radiother Oncol. 2005; 74:235-45. https://doi. org/10.1016/j.radonc.2004.12.015.

21. Dimopoulos JC, Petrow P, Tanderup K, Petric P, Berger D, Kirisits C, Pedersen EM, van Limbergen E, Haie-Meder C, Pötter R. Recommendations from Gynaecological (GYN) GEC-ESTRO Working Group (IV): basic principles and parameters for MR imaging within the frame of image based adaptive cervix cancer brachytherapy. Radiother Oncol. 2012; 103:113-22. https://doi.org/10.1016/j. radonc.2011.12.024.

22. Pötter R, Haie-Meder C, Van Limbergen E, Barillot I, De Brabandere M, Dimopoulos J, Dumas I, Erickson B, Lang S, Nulens A, Petrow P, Rownd J, Kirisits C, and GEC ESTRO Working Group. Recommendations from gynaecological (GYN) GEC ESTRO working group (II): concepts and terms in 3D image-based treatment planning in cervix cancer brachytherapy-3D dose volume parameters and aspects of 
3D image-based anatomy, radiation physics, radiobiology. Radiother Oncol. 2006; 78:67-77. https://doi.org/10.1016/j. radonc.2005.11.014.

23. Pötter R, Dimopoulos J, Georg P, Lang S, Waldhäusl C, Wachter-Gerstner N, Weitmann H, Reinthaller A, Knocke TH, Wachter S, Kirisits C. Clinical impact of MRI assisted dose volume adaptation and dose escalation in brachytherapy of locally advanced cervix cancer. Radiother Oncol. 2007; 83:148-55. https://doi.org/10.1016/j. radonc.2007.04.012.

24. Kramer C, Peschel RE, Goldberg N, Kohorn EI, Chambers JT, Chambers SK, Schwartz PE. Radiation treatment of FIGO stage IVA carcinoma of the cervix. Gynecol Oncol. 1989; 32:323-26. https://doi. org/10.1016/0090-8258(89)90633-1.

25. Million RR, Rutledge F, Fletcher GH. Stage IV carcinoma of the cervix with bladder invasion. Am J Obstet Gynecol. 1972; 113:239-46. https://doi.org/10.1016/0002-9378(72)90773-9.

26. Choi HJ, Roh JW, Seo SS, Lee S, Kim JY, Kim SK, Kang KW, Lee JS, Jeong JY, Park SY. Comparison of the accuracy of magnetic resonance imaging and positron emission tomography/computed tomography in the presurgical detection of lymph node metastases in patients with uterine cervical carcinoma: a prospective study. Cancer. 2006; 106:914-22. https://doi.org/10.1002/cncr.21641.

27. Ramirez PT, Jhingran A, Macapinlac HA, Euscher ED, Munsell MF, Coleman RL, Soliman PT, Schmeler KM, Frumovitz M, Ramondetta LM. Laparoscopic extraperitoneal para-aortic lymphadenectomy in locally advanced cervical cancer: a prospective correlation of surgical findings with positron emission tomography/ computed tomography findings. Cancer. 2011; 117:1928-34. https://doi.org/10.1002/cncr.25739.

28. Gouy S, Morice P, Narducci F, Uzan C, Gilmore J, Kolesnikov-Gauthier H, Querleu D, Haie-Meder C, Leblanc E. Nodal-staging surgery for locally advanced cervical cancer in the era of PET. Lancet Oncol. 2012; 13:e212-20. https://doi.org/10.1016/S1470-2045(12)70011-6.

29. Gerbaulet A, Maher M, Haie-Meder C, Lartigau E, Marsiglia H. Cancer of the cervix: The Paris method. In: Vahrson HW, editor. Radiation Oncology of Gynecological Cancers. New York: Springer; 1997; 198-205.
30. Chargari C, Magné N, Dumas I, Messai T, Vicenzi L, Gillion N, Morice P, Haie-Meder C. Physics contributions and clinical outcome with 3D-MRI-based pulsed-dose-rate intracavitary brachytherapy in cervical cancer patients. Int J Radiat Oncol Biol Phys. 2009; 74:133-39. https://doi. org/10.1016/j.ijrobp.2008.06.1912

31. Haie-Meder C, Chargari C, Rey A, Dumas I, Morice P, Magné N. MRI-based low dose-rate brachytherapy experience in locally advanced cervical cancer patients initially treated by concomitant chemoradiotherapy. Radiother Oncol. 2010; 96:161-65. https://doi.org/10.1016/j. radonc.2010.04.015

32. Mazeron R, Gilmore J, Dumas I, Champoudry J, Goulart J, Vanneste B, Tailleur A, Morice P, Haie-Meder C. Adaptive 3D image-guided brachytherapy: a strong argument in the debate on systematic radical hysterectomy for locally advanced cervical cancer. Oncologist. 2013; 18:415-22. https://doi.org/10.1634/theoncologist.2012-0367

33. Mazeron R, Petit C, Rivin E, Limkin E, Dumas I, Maroun P, Annede P, Martinetti F, Seisen T, Lefkopoulos D, Chargari C, Haie-Meder C. 45 or 50 Gy, Which is the Optimal Radiotherapy Pelvic Dose in Locally Advanced Cervical Cancer in the Perspective of Reaching Magnetic Resonance Image-guided Adaptive Brachytherapy Planning Aims? Clin Oncol (R Coll Radiol). 2016; 28:171-77. https:// doi.org/10.1016/j.clon.2015.10.008

34. International Commission on Radiation Units and Measurements. ICRU report 38: Dose and volume specification for reporting intracavitary therapy in gynaecology. Bethesda; 1985.

35. Dale RG. The application of the linear-quadratic dose-effect equation to fractionated and protracted radiotherapy. Br J Radiol. 1985; 58:515-28. https://doi. org/10.1259/0007-1285-58-690-515.

36. R Core Team. R: a language and environment for statistical computing. Vienna, Austria: R Foundation for Statistical Computing; 2008. Available from http://www.R-project.org/.

37. Therneau T, Grambsch P. Modeling Survival Data: Extending the Cox Model. 1st ed. 2000. Corr. 2nd printing 2001. New York: Springer-Verlag New York Inc.; 2001; 364. 